\title{
THE SATISFACTION LEVEL OF UNDERGRADUATE SCIENCE STUDENTS TOWARDS USING E-LEARNING AND VIRTUAL CLASSES IN EXCEPTIONAL CONDITION COVID-19 CRISIS
}

\author{
Dr. Ali Khaled BAWANEH \\ ORCID: 0000-0002-0507-1743 \\ Deanship of Academic Development \\ Imam Abdulrahman Bin Faisal University \\ Eastern Province, SAUDI ARABIA
}

Received: 01/04/2020 Accepted: 28/05/2020

\begin{abstract}
The study aimed at investigates the science students' satisfaction level of using e-learning and virtual classes in exceptional condition COVID-19 Crisis, in light of three demographic variables: students' specialization, educational level, and GPA. The population consisted of all science students (Physics, Chemistry, Biology, and Mathematics) in the college of science at a university from Eastern Province, Saudi Arabia. The sample comprised of 116 science students. The researcher developed a questionnaire and verified its validity and reliability for collecting data. Some statistical analyses such as mean, standard deviations, and ANOVA tests were conducted to analyze the questionnaire. The results indicated that the satisfaction level of using e-learning and virtual classes by science students is medium in general but with varying degrees from one item to another. The results did not show significant statistical differences at the level $(\alpha=0.05)$ of the use of e-learning and virtual classes for all independent variables: students' specialization, educational level, and GPA. The study included several recommendations; the most important of which is the necessity of providing infrastructure in the university (all colleges) concerning e-learning and educational technology, providing training programs for all university professors and students on how to use e-learning efficiently to boost their competences and skills in utilizing these innovative models.
\end{abstract}

Keywords: COVID-19, satisfaction level, e-learning, virtual classes, science students.

\section{INTRODUCTION}

Education today has become a continuous and endless process. Therefore, it was necessary to work on transforming teaching methods to meet expectations and maintain the continuity of the educational process (Zydney, McKimmy, Lindberg, \& Schmidt, 2019). Learning that initially relied on face-to-face educational environments is now being carried out in an environment driven by computers and digital technologies (Koller, Ng, Do, \& Chen, 2013).

The demand for virtual education is growing more today than ever before (Lakhal, Bateman, \& Bedard, 2017). Today one can hardly find a student or teacher who does not use or know how to use the available virtual learning programs (Koller, Ng, Do, \& Chen, 2013). Some research that focused on learning through virtual learning environments has shown that university heads and faculty see this type of education as a way to reach a larger number of students (Zydney, et al., 2019). However, professors suffer a heavy workload due to high expectations from students who have expressed on the other hand that they appreciate the opportunity offered by virtual learning environments (Cain, Bell, \& Cheng, 2016; Cain, 2015), where education is carried out in a manner that is more independent from the constraints of time and space, and away from traditional education on campus, and they are looking for better educational quality for study programs that use the Internet being less quality (Lakhal, De Sherbrooke, \& Bateman, 2017).

In the virtual learning environment, learners see more opportunities to connect with professors than in traditional classrooms (Olt, 2018). Hundreds of years ago, the first president of the University of Chicago, William Rainer Harper, said: 
"The student who prepared a certain number of lessons through methods similar to what happens in school knows about the topics related to the lessons and can handle those lessons, better than the student who is retired in the classroom." （Nicholas V. Longo. (2007): P37)

With great technical progress and the spread of the Internet at competitive prices, Internet-based education is rapidly developing in universities all over the world (Zydney, et al., 2019; Marshall, 2018; McSweeney, 2010). Higher education institutions are constantly seeking to employ new technologies to become more productive, to manage their development strategies, in addition to effectively rebuilding the curriculum to meet the diverse needs and expectations of students and involve students in learning (Lakhal, De Sherbrooke, \& Bateman, 2017; Ramsey, Evans, \& Levy, 2016; Cain, Bell, \& Cheng, 2016).

E-learning is not only an alternative that is resorted to in times of hardship (Cain, 2015). But rather the principle is that it is seen as a basis of the foundations and pillars of education systems in our countries and that it is employed in a manner that ensures the achievement of the educational return, especially at a time when educators are busy achieving new starting points such as the role of education in achieving sustainable development and implementation of ambitious visions of countries (Raes, Detienne, Windey, \& Depaepe, 2019; Lakhal, De Sherbrooke, \& Bateman, 2017).

In times of crises and hardships, all hands and minds rush to search for alternatives in all fields to overcome these crises and avoid their damages, and education is one of the most important of these areas (Ozgur, 2015; Tami, 2016). Perhaps what is happening today in the world from the spread of viruses and pandemic prompted many governments to stop studying in educational institutions to protect? the learners and the instructors (Kyungmee, 2020). To prevent this harm, several voices called for searching for alternatives that the learning process can continue taking into consideration the dimension and circumstance that the world lives in today, and many opponents of e-learning are convinced that it is the best solution to this crisis (Kyungmee, 2020).

Today, we live in a state of dismay at the spread of Coronavirus in the world. This has led to the disruption of all life in societies, including education and higher education. Countries and educational systems resorted to activating e-learning and virtual classes in completing the rest of the curricula and thinking about effective, enjoyable and practical mechanisms in providing curricula, in addition to thinking about making the final evaluation of students automatic and in a manner that achieves the public interest in achieving the intended learning outcomes (MIT Technology Review, 2020). Where people interested in academic affairs note that the spread of the Coronavirus has made e-learning and virtual classes more prevalent and practiced, and has pushed traditional academics and decision-makers to seriously consider the importance of activating this type of teaching and learning after years of neglect and default, and making it a basic educational pattern alongside the prevailing pattern applicable in normal circumstances (Bawaneh, 2020; MIT Technology Review, 2020).

According to the statistics of the United Nations Educational, Scientific and Cultural Organization (UNESCO) and to preserve the safety of students and teaching staff, more than 61 countries in the world have closed their schools and universities in specific regions or throughout the country and transferred to digital and electronic education for more than 421.4 million students in the world, including (1620491) University student in the Kingdom of Saudi Arabia. The Saudi government authorities announced the closure of universities from March 9, 2020, until further notice (MIT Technology Review, 2020).

Hence, this study came to find out the degree of satisfaction of students of the College of Science at Imam Abdulrahman Bin Faisal University in the Eastern Region of the Kingdom of Saudi Arabia on activating e-learning and teaching methods, direct and indirect virtual classes in providing academic content. Teaching and learning practices at Imam Abdulrahman Bin Faisal university mainly depend on the conventional method, although some courses are offered by employing technology like e-learning, and virtual classes that are embedded within the blackboard. Although the university has been heading for several years to automate the majority of the courses in different colleges, to achieve the goal to make the e-learning a basic pattern alongside regular education. In general, the study aimed to answer the following questions:

1. What is the satisfaction level of the college of science students at Imam Abdulrahman Bin Faisal University towards the use of e-learning and virtual classes in their learning?

2. Do the science students at Imam Abdulrahman Bin Faisal University satisfaction level differ about the use of e-learning and virtual classes in their learning according to their specialization, educational level, and GPA? 


\section{Objectives of the Study}

Measuring the degree of satisfaction of students of the College of Science at Imam Abdulrahman Bin Faisal University about activating e-learning and virtual classes.

Disclosing the presence of statistically significant differences for the satisfaction of students of the College of Science at Imam Abdulrahman Bin Faisal University regarding the activation of e-learning and virtual classes with different variables (Specialization, Academic Level, and GPA).

\section{Operational Definitions}

\section{E-learning}

One of the modern learning methods that provide educational content with a variety of modern electronic media such as the computer, the Internet, the university's academic electronic portal (Blackboard-Learning Management System) and virtual classes that facilitate the process of communication between professors and students, between students themselves and between students and the university; further, it includes simultaneous and asynchronous meetings, multiple media: voice/audio, image, graphics, and electronic libraries, to communicate information to the learner in the best, fastest, least effort consumption and most beneficial way. Further, it promotes students' self-learning and gives freedom in time and space to parties to the educational learning process. Because of the Corona epidemic that sweeps the whole world and the effect of preventing students and teachers from going head-to-head/face-to-face at Imam Abdulrahman Bin Faisal University, the university has to provide the content of science courses for all courses electronically.

\section{Virtual Classes}

An online educational technology that provides a highly interactive classroom environment; allowing learners to engage with meetings; ask questions, whether using written or audio windows; receiving direct responses to these inquiries; conducting discussions; uploading files and other reception; assigning students to manage the classroom and practice discussion processes with their colleagues, and implementing many activities with the efficiency of the classroom without the need for physical presence in the classroom.

\section{Satisfaction Level}

What students of the College of Science at Imam Abdulrahman Bin Faisal University feel, accept and level of happiness of the expected performance towards the use of e-learning and virtual classes at the time of the Corona crisis, which was measured through the questionnaire that the researcher prepared for this purpose.

\section{Context of the Study}

\section{Place Boundaries}

Imam Abdulrahman Bin Faisal University - Dammam, Eastern Province, Saudi Arabia

\section{Human Frontiers}

College of Science - This collage included Female students only.

\section{Time Limits}

The second semester of the academic year 2019/2020.

\section{Situational Boundaries}

The spread of the Corona pandemic COVID-19. 


\section{LITERATURE REVIEW}

Some educators object to e-learning on the pretext of poorly adjusting its tools accurately compared to traditional learning, but the follower of the e-learning journey realizes that the more technology and Internet tools and technologies develop the more the educational employment develops to serve learning goals (Cain, Bell, \& Cheng, 2016; Zydney, et al., 2019; Ramsey, Evans, \& Levy, 2016; Tami, 2016).

The control of teaching and attendance operations and the processes of simultaneous and synchronous interaction became widely available in the learning management systems (LMS) efficiently and easily (Lakhal, De Sherbrooke, \& Bateman, 2017; Bateman, 2017), in addition to the means of controlling the electronic evaluation processes remotely in a way that fulfills the expectations of those in charge of achieving the principle of measurement and evaluation without cheating or Fraud (Cain, Bell, \& Cheng, 2016; Zydney, et al., 2019; Ramsey, Evans, \& Levy, 2016). Control and regulating procedures are still ongoing and have criteria that achieve real learning outcomes (Raes, et al., 2019).

Here, it must be noted that LMS can manage the educational institution and the teaching-learning processes in a coordinated and largely disciplined manner; and enable students to interact and perform all learning tasks interactively (Zydney, et al., 2019; Alshorman and Bawaneh, 2018). Through Content Management Systems (CMS), various educational resources can be arranged and organized in a way that can help the university faculty and the learner achieve distinctive educational goals (Alshorman and Bawaneh, 2018).

Many tools, applications, and technologies can be employed such as virtual learning: augmented reality, mixed reality, virtual learning environment, personal learning environments (PLEs), and learning platforms for online courses available via the Internet MOOCs; in addition to employing motivational Gamification and Interactive video, as well as artificial intelligence, which is expected to play a big role soon, in addition to many other educational technology developments that are developing rapidly related to the development and acceleration of the spread of digital technology (McSweeney, 2010; Annelies et al., 2020).

\section{Benefits of a Virtual Classroom}

Many researchers and those interested in the educational technology (Walden University, 2020; Lakhal, De Sherbrooke, \& Bateman, 2017; Bateman, 2017; Cain, 2015; Raes, et al., 2019) have pointed out many of the benefits of e-learning and virtual classes, summarized as follows:

\section{Access to coursework from anywhere at any time.}

A student has the freedom to study and complete his lessons 24/7 from anywhere and at any time that suitable for the busy schedule. All you need is a laptop or another smart device. Once you log in to the student portal, you can access assignments, send homework, cover faculty presentations, join classmates' discussions, do research, communicate with your teacher and classmates, get assistance, receive feedback, and access test grades.

\section{Combination of structure and freedom.}

Coursework built on a structure of weekly assignments and due dates that you have to meet, like an online test; posting homework, articles, and projects; watching a faculty presentation; or participating in a student portal discussion. You are free to choose a suitable time to participate that aligns with your schedule.

\section{Management your time effectively}

E-learning provides a rich environment for working adults who need to balance work and family with the new demands of going back to university

\section{Expanded world view}

Attract students around the world; bring diversity perspectives from different cultures.

\section{Asynchronous discussions with classmates}

Students can attend class from anywhere, participating in discussions, adding posts, submitting lessons, and working perfectly. 


\section{Immediate feedback on tests}

You don't have to worry and wait for days for test results. You take your tests online, and they are usually scored when you finish. You can quickly see where you did well and where you need development.

\section{Sharpened digital skills}

While increasing your knowledge and skills in your area of study, you'll also enhance your digital skills on the most updated online learning technology.

\section{Kind of Technologies Using in E-Learning and Virtual Classes}

A recent survey on the use of learning technologies highlighted a range of technologies in use in higher education institutes in the region. These included:

1. Audio/Podcasting (Voice Recorders)

2. Video (Video Conferencing, Echo360)

3. Collaborative Learning Tools (Blogs, Voting Tools)

4. Resource Development Tools (Articulate, Wimba Create)

5. Web Tools (YouTube, Delicious)

6. SMART Technologies (Interactive Whiteboards)

7. Assessment Tools (Moodle, Blackboard)

8. Synchronous Learning Tools (Breeze, Blackboard)

9. Portfolio Tools

\section{Some Reasons for Using E-Learning and Virtual Classes}

McSweeney (2010) mentioned the facilities for how it is easy to use the e-learning and educational technologies in teaching and learning like:

1. Ease of setting up the environment

2. Ease of connection and enter the room.

3. Ease of participant's communication.

4. Ease of sharing documents.

5. Ease of collaboration.

6. Ease of recording and archiving the classes.

7. Customization of the interface.

Regarding the study of the effect of e-learning and virtual synchronous or asynchronous on student achievement and determining their attitudes towards them in various courses, several studies (Ozgur, 2015; Miltiadou \& Savenye, 2003; Wang \& Newlin, 2012; Glenda, Joslyn, \& Mariel, 2019) found that e-learning and virtual classes are effective in enhancing students' achievement, increasing their motivation and selfconfidence, and enhancing communication skills with colleagues and professors. These studies also praised the importance of re-sending the registration for the concurrent virtual class as it allows students to refer to it many times at the appropriate time and place for them; this increases students' understanding of the content and improves their attitudes towards learning in general. This is confirmed by several studies, including (Abu Aqel, 2012; Trotter, 2007; Al-Shammari, 2007), as they emphasized that e-learning improves university students' learning of science courses, with the emergence of statistically significant differences between males and females in favor of females, this may be caused by the commitment of females in the home more, and their interest in the study is superior to that of males. On the other hand, Al-Huthaifi's (2008) study of the effectiveness of e-learning did not improve the students' attitudes towards learning. Recently, Alakharas (2018) studied the effect of e-learning on student achievement in mathematics compared to the usual method. The findings indicated the positive impact of e-learning on students' achievement in mathematics; while the findings did not show differences due to the gender of the teacher and his/her specialization. In the same 
context, AlSaedy et. al (2017) studied the effect of e-learning in teaching mathematics on achievement and student attitudes towards the course in the Sultanate of Oman. The findings of this study were in line with the Alakharas (2018) study and other studies with the positive impact of e-learning on students' achievement and enhancing their attitudes towards the course. Very recently, Annelies Raes et. al (2020) studied the effect of the use of hybrid and virtual classes on the degree of integration and interaction of students and their performance. Although the hybrid and virtual classes are promising and support student achievement, they give them flexibility and freedom to choose the time and place they prefer to attend lectures (being online). However, the findings showed that students' motivation and integration with colleagues were very little in virtual learning. This may be because the current generation is digital native, and initiative always looking for modern, fast, advanced applications that contain fun, achieve benefit and increase the interaction of all parties to the teaching-learning process. This in itself is considered by the study point of view to be one of the challenges facing the educational process.

To study the requirements and obstacles of e-learning, some researchers (Al Saif, 2009; Alshahrani, 2010) have found out the importance of e-learning despite the many administrative and teaching burdens as well as the overlap of administrative and academic burdens and the lack of opportunities to attend professional development programs for university professors about e-learning, virtual classes, and technology employment in teaching and learning. All of these factors reduce their ability and motivation to use technology in higher education.

In the same context, Tami's (2016) study came to confirm the importance of virtual university learning and showed that it is a manifestation of scientific and technological progress, as it contributes to human development. The study recommended the importance of holding training programs to enable university professors to employ e-learning and virtual classes and their tools to enhance teaching and learning.

\section{METHOD AND PROCEDURES}

To achieve the objectives of the study, the researchers followed the descriptive-analytical method.

\section{Study Population}

The population of the study is composed of all students in the college of science at Imam Abdulrahman Bin Faisal University for the academic year 2019/2020. The number of students is (2100). The study sample was selected by stratified random sampling according to the study variables. The results were analyzed in the light of the sample as shown in table (1).

Table 1. Study sample of students

\begin{tabular}{cccc}
\hline & Variable & Number & $\%$ \\
\hline \multirow{3}{*}{ Specialization } & Physics & 33 & $28 \%$ \\
& Chemistry & 38 & $33 \%$ \\
& Biology & 37 & $32 \%$ \\
& Math & 08 & $7 \%$ \\
& Total & 116 & $100 \%$ \\
\hline \multirow{2}{*}{ Edu_Level } & $1^{\text {st } \text { Year }}$ & 07 & $6 \%$ \\
& $2^{\text {nd }}$ Year & 25 & $22 \%$ \\
& $3^{\text {rd }}$ Year & 29 & $25 \%$ \\
& $4^{\text {Th Year }}$ & $47 \%$ \\
GPA & Total & 55 & $100 \%$ \\
\hline & Excellent & 116 & $24 \%$ \\
& V.good & 28 & $49 \%$ \\
& good & 57 & $23 \%$ \\
\end{tabular}


Table (1) shows that the sample included 116 students, 33 of which are Physics, 38 Chemistry, 37 Biology, and 08 Mathematic students. They were distributed over the four years by $06 \%, 22 \%, 25 \%$, and $47 \%$, respectively. As regards GPA, they represent $24 \%$ from the excellent level, $49 \%$ from the very good level, $23 \%$ from the good level, and only $04 \%$ from the less than good level. The decrease in the response rate to the questionnaire may due to the coincidence of the data collection period with the mid-term test, the presence of many researchers collecting data for different research purposes as well as students' anxiety and fear of the epidemic.

\section{Instrumentation}

The researcher reviewed the theoretical literature related to teaching and e-learning that employs the e-learning and virtual classes. He elaborated on the research instrument according to the Likert Scale with six levels (strongly agree, agree, slightly agree, slightly disagree, disagree, strongly disagree). The tool aimed at measuring the satisfaction level of science university students towards the use of e-learning and virtual classes in students' learning.

\section{Validation of the Instrument}

To check the validity of the research instrument, the initial version was consisting of 32 items validated by six experts who are members of the teaching staff (three of them in science education, two in educational technology, and one in psychology) at Imam Abdulrahman Bin Faisal University. Some items were deleted, and the wording of several items as amended. The number of items in the developed version was 27.

\section{Reliability of the Instrument}

To calculate the reliability of the instrument, the researcher applied the tool one time only for 35 science students from the Deanship of preparatory year and supporting studies. Then, he calculated the Cronbach Alpha coefficient, the reliability coefficient was 0.86 . This value was considered acceptable in the social sciences to achieve the purpose of the current study (Obiedat et al., 2016; Al-Kellani; and Al-Shraifeen, 2011).

\section{Statistical Standard}

The following equation was adopted for paragraphs classification (Al-Rashidi, 2018; Bawaneh, \& Moumene, 2020).

$$
\begin{aligned}
& =(\text { Upper limit of scale }- \text { minimum scale }) / \text { number of required categories } \\
& =(6-1) / 3 \\
& =1.67
\end{aligned}
$$

The categories are (1 - 2.67: Weak (W), 2.68 - 4.35: Medium (M), and 4.36 - 6.0: Strong (S)).

\section{RESULTS}

To answer the first question of the study: "What is the satisfaction level of the college of science students at Imam Abdulrahman Bin Faisal University towards the use of e-learning and virtual classes in their learning?" The researcher calculated the Mean and the standard deviation of the instrument items prepared for this purpose, and the results were cast on Table (2). 
Table 2. Means, SD, and the Category for all instrument items ( $\mathrm{N}=116)$

\begin{tabular}{|c|c|c|c|c|}
\hline No & Items & Mean & SD & Category \\
\hline 1. & I love learning via the computer and the internet & 4.15 & 1.16 & M \\
\hline 2. & I think knowledge of e-learning skills and virtual classes is necessary for every student & 5.08 & 0.94 & $S$ \\
\hline 3. & E-learning lectures and virtual classes save my time and effort & 4.33 & 1.50 & M \\
\hline 4. & I think e-learning and virtual classes motivate me to think creatively & 2.96 & 1.66 & W \\
\hline 5. & Feel enjoying learning through e-learning and virtual classes & 3.75 & 1.59 & M \\
\hline 6. & I think e-learning and virtual classes give me more self-confidence & 3.85 & 1.64 & M \\
\hline 7. & E-learning and virtual classes develop my research and investigation skills & 4.37 & 1.47 & S \\
\hline 8. & Using e-learning and virtual classes is a suitable solution at a time of the pandemic & 5.43 & 1.01 & S \\
\hline 9. & Using e-learning and virtual classes help with self-learning in science & 4.49 & 1.26 & $S$ \\
\hline 10. & I prefer using e-learning and virtual classes in normal circumstances & 3.62 & 1.60 & M \\
\hline 11. & Using e-learning and virtual classes help in learning scientific concepts & 3.80 & 1.43 & M \\
\hline 12. & Using e-learning and virtual classes help in cooperative learning (groups) & 3.31 & 1.57 & M \\
\hline 13. & Using e-learning and virtual classes develop my ability to solve problems & 3.98 & 1.42 & M \\
\hline 14. & $\begin{array}{l}\text { Learning through e-learning and virtual classes increase the interaction between the } \\
\text { student and the instructor }\end{array}$ & 3.32 & 1.63 & M \\
\hline 15. & $\begin{array}{l}\text { E-learning and virtual classes do not take into account the diversity among learners } \\
\text { (individual differences, patterns of thinking, motivation, ...) }\end{array}$ & 4.27 & 1.36 & M \\
\hline 16. & $\begin{array}{l}\text { I think that learning with conventional teaching methods gives better results than } \\
\text { e-learning and virtual classes }\end{array}$ & 4.67 & 1.36 & $\mathrm{~S}$ \\
\hline 17. & I think e-learning and virtual classes limit freedom of thinking & 3.72 & 1.37 & M \\
\hline 18. & The use of e-learning and virtual classes adds a new burden to students & 3.98 & 1.55 & M \\
\hline 19. & E-learning and virtual classes weaken social cohesion among students & 4.31 & 1.44 & M \\
\hline 20. & $\begin{array}{l}\text { I do not feel comfortable assigned to a job/assignment through e-learning and } \\
\text { virtual classes }\end{array}$ & 3.73 & 1.69 & M \\
\hline 21. & Regular learning methods are preferred over e-learning and virtual classes & 4.36 & 1.44 & $S$ \\
\hline 22. & I don't trust e-learning and virtual classes & 3.42 & 1.51 & M \\
\hline 23. & I am concerned and afraid of e-learning and virtual classes & 3.43 & 1.53 & M \\
\hline 24. & I believe the money spent on e-learning and virtual classrooms being wasted & 2.51 & 1.34 & W \\
\hline 25. & $\begin{array}{l}\text { The large number of courses offered by e-learning and virtual classes increased my } \\
\text { anxiety, tension, and fear over my results }\end{array}$ & 4.56 & 1.46 & $\mathrm{~S}$ \\
\hline 26. & I have a real conviction of the usefulness of e-learning and virtual classes & 4.25 & 1.20 & M \\
\hline 27. & $\begin{array}{l}\text { I need training programs to help me use e-learning systems and virtual classes } \\
\text { efficiently }\end{array}$ & 3.48 & 1.55 & $S$ \\
\hline \multicolumn{4}{|c|}{3.97} & $M$ \\
\hline
\end{tabular}

The results on Table (2) show that the Mean for the students of the science college is generally (3.97), this shows that their satisfaction level towards using the e-learning and virtual classes in learning was Medium. And when we look to the Category for all instrument items, we can see that there are 8 items strong, 17 items with $63 \%$ Medium, and only two out of 27 items were weak. The highest Mean is 5.43 corresponding to the eighth item, which indicates that using e-learning and virtual classes is a suitable solution at a time of the pandemic. This was followed directly by the items number two and sixteen with a calculation Mean of 5.08, and 4.67 respectively. The second item indicates that the students think the knowledge of e-learning skills and virtual classes is necessary for every student, whereas item sixteen indicates that the students prefer the conventional teaching methods comparative with the e-learning and virtual classes.

However, the twenty-fourth item came in the last order in terms of the calculation Mean of 2.51. This item addresses that the money spent on e-learning and virtual classrooms being wasted. This followed by item number four with a Mean of 2.96, which shows learning by using e-learning and virtual classes did not enhance creative thinking. These results support each other.

To answer the second question: "Do the science students' at Imam Abdulrahman Bin Faisal University satisfaction level differ about the use of e-learning and virtual classes in their learning according to their specialization, educational level, and GPA?" The researcher calculated the statistical Means and standard deviations associated with the independent variables as shown in Table (3). 
Table 3. Means and standard deviations of students' satisfaction level towards e-learning and virtual classes

\begin{tabular}{cccc}
\hline & Variable & Mean & SD \\
\hline & Physics & 4.03 & 0.477 \\
Specialization & Chemistry & 3.90 & 0.510 \\
& Biology & 3.96 & 0.465 \\
& Math & 4.05 & 0.716 \\
& Total & 3.97 & 0.499 \\
\hline \multirow{2}{*}{ Edu_Level } & $1^{\text {st }}$ Year & 4.11 & 0.303 \\
& $2^{\text {nd }}$ Year & 4.01 & 0.578 \\
& $3^{\text {rd }}$ Year & 3.90 & 0.628 \\
& $4^{\text {Th } \text { Year }}$ & 0.403 \\
& Total & 3.96 & 0.499 \\
\hline & Excellent & 3.97 & 0.637 \\
& V. good & 3.97 & 0.413 \\
& good & 3.94 & 0.406 \\
& Less than good & 3.93 & 0.837 \\
\hline
\end{tabular}

Table (3) refers to the calculation Mean and standard deviations of students' satisfaction towards using the e-learning and virtual classes according to the variables: specialization, educational level, and GPA.

We find a difference in the calculation Mean between students' specialization. Where the calculation Mean of math students is the highest with 4.05 and the standard deviation is 0.716 . Whereas the lowest mean is 3.90 for Chemistry students with a standard deviation of 0.510 . The results showed that the Mean of the students in the first year level was the highest among all the educational level with a Mean of 4.11 and a standard deviation of 0.303 . The $2^{\text {nd }}$ year scored 4.01 with a standard deviation of 0.578 . The lowest Mean 3.90 was attributed to the $3^{\text {rd }}$ year students with a standard deviation of 0.628 .

Regarding the satisfaction of students' use of e-learning and virtual classes according to their GPA, Table (3) indicates that the category of students with less than good is the most satisfaction group towards the use of the e-learning and virtual classes with Mean of 4.45 and a standard deviation of 0.499 . Yet, the satisfaction of the good and very good categories was the lowest with Mean of 3.93, and 3.94 respectively, and a standard deviation of 0.406 , and 0.413 . By reading the above results, we find that there are apparent differences in the calculation Mean of the satisfaction level of the science students at Imam Abdulrahman Bin Faisal University according to the variables of specialization, educational level, and GPA. To ascertain the validity of the differences, the researcher performed the ANOVA analysis, and the results were presented in Table (4).

Table 4. ANOVA test of students' satisfaction level towards e-learning and virtual classes

\begin{tabular}{|c|c|c|c|c|c|}
\hline & Sum of Squares & df & Mean Square & $\mathrm{F}$ & Sig. \\
\hline \multicolumn{6}{|l|}{ Specialization } \\
\hline Between Groups & .392 & 3 & .131 & 0.517 & 0.672 \\
\hline Within Groups & 28.340 & 112 & .253 & & \\
\hline Total & 28.732 & 115 & & & \\
\hline \multicolumn{6}{|l|}{ Educational Level } \\
\hline Between Groups & .339 & 3 & .113 & 0.446 & 0.721 \\
\hline Within Groups & 28.393 & 112 & .254 & & \\
\hline Total & 28.732 & 115 & & & \\
\hline \multicolumn{6}{|l|}{ GPA } \\
\hline Between Groups & 1.226 & 3 & .409 & 1.665 & 0.179 \\
\hline Within Groups & 27.506 & 112 & .246 & & \\
\hline Total & 28.732 & 115 & & & \\
\hline
\end{tabular}


Table (4) shows that there are no statistically significant differences for all the independent variables in the current study: students' specialization, educational level, and their GPA on the satisfaction level towards the use of e-learning and virtual classes. The statistical significance values at $(\alpha=0.05)$ were $(0.672, F=0.517)$, $(0.721, \mathrm{~F}=0.446)$, and $(0.179, \mathrm{~F}=1.665)$ respectively.

\section{DISCUSSION}

To answer the findings of the first question, which states "What is the satisfaction level of the college of science students at Imam Abdulrahman Bin Faisal University towards the use of e-learning and virtual classes in their learning?” The average satisfaction level for students of the College of Science at Imam Abdulrahman Bin Faisal University about e-learning and virtual classes is (3.97). This can be explained that this type of learning has come as an appropriate solution at an exceptional time to provide the remaining courses, postpone them, or cancel the entire semester. Therefore, the efforts of students and instructors are kept from the beginning of the semester. This was confirmed by many students in their tweets on social media, thanks to the efforts made by the university and the great eagerness to present the courses continuously and with high professionalism, smoothness, and organization.

At the same time, this type of learning did not meet with sufficient acceptance and did not meet the expectations and needs of students; as they are used to direct face-to-face learning; conducting operations in laboratories; cooperative work; and direct discussion with colleagues and the professor; in addition to peer learning. On the other hand, the emergence of infrastructure-related problems with e-learning requirements such as increased demand on the Internet and pressure on the university network, which faces difficulty in accessing virtual hours at times. Furthermore, learning has become essentially dependent on students, which requires more duties along with multiple courses, and a shortage of time led to a decline in the level of students' satisfaction with e-learning. Moreover, the psychological state of students should be taken into consideration due to the fear of infection with the COVID-19, and concern about the mechanisms of evaluation using the calculation of their grades. This is confirmed by many students in their tweets on social media regarding their concerns about the evaluation of their learning, the mechanisms for providing various tests, as well as a large number of burdens and duties.

E-learning and virtual classes deal with all spectrums of students with the same mechanism. Some students may not like to learn using technology while others are willing and constantly seek to use technology in their learning. This is in addition to the differences between the level of faculty members' mastery of technology; diversification of activities; and learning aids that may help students learn; such as videos, analogy, some modern applications that use brainstorming, structural evaluation, dry laboratories, and others.

All of the above can be considered as an explanation of the average level of students' satisfaction with the use of e-learning and virtual classes in their learning, and this, of course, reflects the high responsibility of students in the exceptional conditions and their respect of the efforts of the university in overcoming the difficulties and obstacles that face this type of learning, and facilitating students' access to the university's learning platforms, and obtaining their right to learn appropriately to achieve the learning outcomes as in normal circumstances.

By reviewing student tweets on social media regarding e-learning, we find different opinions. Some students complain about the weakness of the Internet and the great pressure on the Internet, which prevents attending lectures and virtual classes. Some of them say the voice is not clear at all. Some also say that the explanation is not clear, and that many subjects - in physics, chemistry, and biology - need laboratories and practice. This is in addition to the fact that many students are very concerned about the final exam, and they hope that it will be in the normal way instead of online tests. On the other hand, we find some students thanking the university for its great efforts in providing all the necessary electronic services to continue their teaching and describe the services as world-class. They also thank the efforts of the instructors and the Deanship of E-Learning and Distance Learning for the great efforts, day and night, to overcome difficulties and facilitate students' learning.

This result supported by many types of research that targeted the students' attitudes and satisfaction levels about using technology and blackboard in teaching and learning (Ozgur, 2015; Miltiadou \& Savenye, 2003; 
Wang \& Newlin, 2012; Glenda, Joslyn, \& Mariel, 2019; Abu Aqel, 2012; Trotter, 2007; Al-Shammari, 2007).

To answer the second question of the study which states "Do the science students' at Imam Abdulrahman Bin Faisal University satisfaction level differ about the use of e-learning and virtual classes in their learning according to their specialization, educational level, and GPA?". The findings showed that there are no statistically significant differences in the level of satisfaction level of students of the College of Science at Imam Abdulrahman Bin Faisal University about e-learning and virtual classes attributed to all the independent variables of the study: scientific specialization (physics, chemistry, biology, and mathematics), academic level (first year, second, third, and fourth-year), and GPA (excellent, very good, good, less than good). This can be attributed by many reasons, the most important of which are:

1. All members of the study sample from the College of Science and the programs in this college (physics, chemistry, biology, and mathematics) programs are fairly close with some minor differences. Where the requirements and needs of students related to content coverage. For achieving some of them and decreasing others were the same for everyone, therefore, no differences with statistical significance appear.

2. Students' way of thinking is close (from one college), and their technical information and dealings with technology are also close.

3. According to the system and rules at the University of Imam Abdulrahman Bin Faisal, the acceptance and admission criteria apply to everyone/ candidates, hence, all students who join the College of Science have similar characteristics when entering the college. During their studies in the various departments in the college, changes occur in maturity, and the acquisition of knowledge and skills, however, they did not rise to make significant differences in their level of satisfaction with the use of e-learning and virtual classes in the exceptional time represented by the spread of the pandemic COVID-19.

4. E-learning and virtual classes were applied to everyone suddenly, and in the same circumstance, which is the spread of the pandemic COVID-19, although there was a previous application of technology and e-learning from some professors to some courses at different levels even they were individual experiences.

5. Lack of experience for most of the students, regardless of specialization, academic level and GPA in how to use e-learning and virtual classes. This, of course, puts all students at the same level of contentment.

6. All students have the same concerns and anxieties because of the required tasks, duties, and projects to complete different requirements as well as grades at the end of the semester.

The findings of this study are consistent with the results of some studies (Abu Aqel, 2012; Trotter, 2007; AlShammari, 2007; AlSaedy et. al., 2017; Alakharas, 2018; Annelies Raes et. al., 2020). They also differ from the findings of the study of Al-Huthaifi's (2008) and Annelies Raes et. al (2020).

\section{CONCLUSION}

The current study aimed to measure the level of satisfaction of students of the College of Science at the University of Imam Abdulrahman Bin Faisal towards the use of e-learning and virtual classes in the exceptional circumstance, which is the spread of the pandemic COVID-19, this led to a decision to convert all teaching and learning activities and practices into electronic. The average students' satisfaction level towards using e-learning and virtual classes was Medium, and there were no statistically significant differences due to the difference in specialization, academic level, and GPA. Furthermore, many problems are accompanying this procedure; the most important of which is the weakness of the Internet and the difficulty of accessing the virtual classes; the large number of burdens required from students and instructors; and the lack of familiarity of students with this type of learning, in addition to anxiety and fear of the disease and its impact on the psychological status of students, their academic performance and their achievement of success in the courses of the semester. 


\title{
Recommendations
}

1. Accrediting higher education institutions (universities) for e-learning along with conventional education

2. Providing infrastructure in the university (all colleges) concerning teaching and e-learning.

3. Providing training programs for all faculty members at the universities on how to use e-learning efficiently.

4. Training students at the university during the preparatory year period on the mechanisms of using e-learning and employing technology in learning.

5. Conducting various studies on the effectiveness of e-learning on student learning from the viewpoint of students, professors, challenges, and solutions mechanisms.

\section{BIODATA and CONTACT ADDRESSES of AUTHOR}

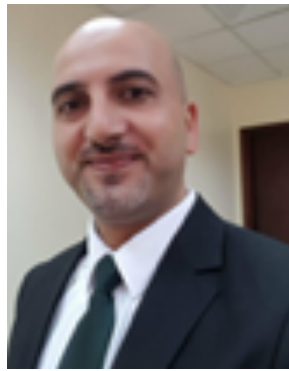

Dr. Ali Khaled BAWANEH is an Assistant Professor in the Deanship of Academic Development, Imam Abdulrahman Bin Faisal University. Dr. Bawaneh gained his Ph.D in Curriculum and Instruction/Science Education at Augest, 2011. He has achieved the status of Fellow (FHEA) based on UK Standerds Framework for teaching and learning. Dr. Bawaneh Certified as a Senior Trainer. His academic interest areas are teaching principles and methods, curriculum development, teacher training, misconceptions in science, teaching and learning, academic profisional development, educational technology. He has over than 23 journal articles published in international indexes, one international book and other national and international articles, papers submitted to international meetings.

\author{
Ali Khaled BAWANEH \\ Deanship of Academic Development \\ Address: Imam Abdulrahman Bin Faisal University \\ P.O. Box 10674, Dammam 31443, \\ Eastern Province, Saudi Arabia \\ Phone: +966595636690 \\ E-mail: akbawaneh@iau.edu.sa; akbawaneh@gmail.com
}

\section{REFERENCES}

Abu Aqel, W. (2012). The effect of using e-learning in teaching science on academic achievement for AlQuds Open University students. Palestinian Journal of Open Education, 3(6), 115-138.

Al-Akharas, Y. (2018). The Impact of the Application of e-Learning Strategy on Academic Achievement in Mathematics in Basic Grades in the Capital Governorate From the Perspective of Teachers of Mathematics, Dirasat: Educational Sciences, 45(4), 70-80.

Al-Kellani and Al-Shraifeen. (2011). Introduction to research in education and social sciences. Third Edition, Dar Al Masirah for Publishing, Distribution, and Printing. Amman, Jordan.

Al-Huthaifi, K. (2008). The effect of teaching electronically on students' achievement, mental ability, and attitude science of the $9^{\text {th }}$ Grade students, Journal of educational sciences, King Saud University, 20(3), 675-715.

Al-Rashidi, F. (2018). The level of using the reflective practices among secondary school teachers-from their points of view- in the Baredah governorate. Journal of Faculty for Basic Education in Educational and Human Sciences / Babel University, April (38), 284-294.

Al-Saedy, M., Alkahaly, Kh., Alpraky, M., Albloshy, A., \& Alkhrousy, H. (2017). The Effect of e-Learning in Teaching Mathematics on Academic Achievement and Attitude towards the Subject for Grade 5 Students in the Sultanate of Oman, International Journal of Educational Specialist. 6(4), 227-239. 
Al Saif, M. (2009). The availability of the e-learning competencies, challenges, and methods of development from the viewpoint of faculty members in the College of Education at King Saud University, unpublished master's thesis, College of Education, King Saud University, Saudi Arabia.

Al-Shahrani, N. (2010). The demands of using e-learning in teaching natural sciences in higher education from specialists, unpublished Ph.D. thesis, College of Education, Umm Al-Qura University, Saudi Arabia.

Al-Shammari, M. (2007). The effect of using integrated learning in teaching geography on the attainment and attitudes of middle school students in Hafar Al-Batin Governorate. Ph.D. thesis, University of Jordan, Amman, Jordan.

Al-Shorman, B., \& Bawaneh, A. (2018). Attitudes of Faculty Members and Students towards the Use of the Learning Management System in Teaching and Learning. The Turkish Online Journal of Educational Technology, 17 (3), 1-15. https://files.eric.ed.gov/fulltext/EJ1184192.pdf.

Annelies, R., Pieter, V., Marieke, P., Ine, W., Wim, V., \& Fien, D. (2020). Learning and instruction in the hybrid virtual classroom: An investigation of students' engagement and the effect of quizzes. Computers \& Education. https://doi.org/10.1016/j.compedu.2019.103682.

Bawaneh, A. (2020). Science Teachers' Satisfaction Level of Professional Development Programs in Enhancing their Teaching Practices. Talent Development \& Excellence, 12, (3s), 1848-1865.

Bawaneh, A. K., Moumene, A. B. H., \& Aldalalah, O. (2020). Gauging the Level of Reflective Teaching Practices among Science Teachers. International Journal of Instruction, 13(1), 695-712. https:// doi.org/10.29333/iji.2020.13145a.

Cain, W. (2015). Technology navigators: An innovative role in pedagogy, design, and instructional support. In P. Redmond, J. Lock, \& P. Danaher (Eds.). Educational innovations and contemporary technologies: Enhancing teaching and learning (pp. 21-35). UK: Palgrave Macmillan.

Cain, W., Bell, J., \& Cheng, C. (2016). Implementing robotic telepresence in a synchronous hybrid course. Proceedings - IEEE 16th international conference on Advanced learning technologies, ICALT: Vol. 2016, (pp. 171-175). https://doi.org/10.1109/ICALT.2016.79.

Glenda, K., Joslyn, H., \& Mariel, P. (2019). Virtually connected. International Teacher Magazine (IMT). It was accessed on 20/03/2020. https://consiliumeducation.com/itm/2019/06/22/virtuallyconnected/.

Koller, D., Ng, A., Do, C., \& Chen, Z. (2013). Retention and intention in massive open online courses: Indepth. Educause Review. Retrieved from http://er.educause.edu/articles/2013/6/retention-andintention-in-massive-open-onlinecourses-in-depth.

Kyungmee, L. (2020). Coronavirus: universities are shifting classes online - but it's not as easy as it sounds. It was accessed on 22/03/2020. Website link: https://theconversation.com/coronavirus-universitiesare-shifting-classes-online-but-its-not-as-easy-as-it-sounds-133030.

Lakhal, S., Bateman, D., \& Bedard, J. (2017). Blended synchronous delivery modes in graduate programs: A literature review and its implementation in the master teacher program. Collected Essays on Learning and Teaching, 10, 47-60. https://doi.org/10.22329/celt.v10i0.4747.

Lakhal, S., De Sherbrooke, U., \& Bateman, D. (2017). The blended synchronous delivery mode in graduate programs: A literature review and its implementation in the master teacher program. Collected Essays on Learning and Teaching, 47-60. https://doi.org/10.22329/celt.v10i0.4747.

Marshall, S. J. (2018). Shaping the university of the future: Using technology to catalyze change in university learning and teaching. Retrieved from https://link.springer.com/book/10.1007\% 2F978-981-10-7620-6.

McSweeney, D. (2010). A framework for the comparison of virtual classroom systems. NAIRTL/ LIN Conference on Flexible Learning at the Royal College of Surgeons. Dublin, Ireland. October 2010. 
Miltiadou M., \& Savenye W. C. (2003). Applying Social Cognitive Constructs of Motivation to Enhance Student Success in Online Distance Education, Educational Technology Review, 11 (1).

MIT Technology Review. (2020). Arab countries resort to distance education to face the repercussions of the Coronavirus. It was accessed on 22/03/2020. https://technologyreview.ae/

Nicholas V. Longo. (2007). Why community matters connecting education with civic life. State University of New York Press, 194 Wahington Avenue, Suite 305, Albany, NY12110-2384.

Obiedat, D. H; Kayed, A; \& Adass, A. (2016). Scientific research: understandable, tools and methods. Dar Alfiker: Publishers and distributors. Amman, Jordan.

Olt, P. A. (2018). Virtually there: Distant freshmen blended in classes through synchronous online education. Innovative Higher Education, 43(5), 381-395. https://doi.org/10.1007/s10755-018-9437-z.

Ozgur, Y. (2015). The Effects of "Live Virtual Classroom" on Students' Achievement and Students' Opinions about "Live Virtual Classroom" at Distance Education. The Turkish Online Journal of Educational Technology, 14(1).108 - 115. https://www.researchgate.net/publication/282889631.

Raes, A., Detienne, L., Windey, I., \& Depaepe, F. (2019). A systematic literature review on synchronous hybrid learning: gaps identified. Accepted for publication in Learning Environments Research.

Ramsey, D., Evans, J., \& Levy, M. (2016). Preserving the seminar experience. Journal of Political Science Education, 12(3), 256-267. https://doi.org/10.1080/15512169.2015.1077713.

Tami, Th. (2016). Academic Virtual Learning (Towards Virtual University). Journal of Diyala. 71, 47-68.

Trotter, A.(2007). School Subtracts Math Texts Add E-Lessons, Tests. Education Week, 26 (36) 10-11.

Walden University. (2020). Online learning has many benefits, one of which is the flexibility afforded by the virtual classroom. It was accessed on 18/03/2020. https://www.waldenu.edu/programs/resource/ seven-benefits-of-a-virtual-classroom.

Wang, A. Y. \& Newlin, M. H. (2012). Online Lectures: Benefits for the Virtual Classroom. T.H.E. Journal. It was accessed on 20/03/2020, http://www.thejournal.com/articles/15513.

Zydney, J. M., McKimm, P., Lindberg, R., \& Schmidt, M. (2019). Here or their instruction: Lessons learned in implementing innovative approaches to blended synchronous learning. Tech Trends, 63(2), 123-132. https://doi.org/10.1007/s11528-018-0344-z. 